\title{
Project cost Management Strategy based on Big Data and BIM
}

\author{
Ping $\mathrm{Wu}^{1}$ \\ ${ }^{1}$ Urban Vocational College of Sichuan, Sichuan, China, 610101
}

\begin{abstract}
With the development of socialist market economy, the current project cost management system in China has gradually exposed some disadvantages, which affect the normal operation and development of construction enterprises to a certain extent. This paper analyzes the research status of PCM, discusses the characteristics of BD technology, the concept of BIMT and the concept of PCM, and finds the method of mutual information feature selection. The results show that in 2020, the output value of construction projects in China is the largest, with 5.54 billion yuan in the first quarter, 5.83 billion yuan in the second quarter, and 6.77 billion yuan in the third quarter. Due to the large number of participants, long construction period and large amount of information in the construction process, these greatly increase the difficulty of PM, but also increase the difficulty of PCM, making some cost problems easier to appear.
\end{abstract}

\section{Introduction}

With the rapid development of China's economy, the competition between construction enterprises is becoming increasingly fierce. To ensure that enterprises will not be eliminated in the competition, the key to success is to do a good job in PCM, strictly control project funds, and grasp every specific link in the whole process.

With the information technology provides a strong guarantee for the PCM, solving many problems in the PCM from the technical level plays a vital role in its application. Many experts have studied the project cost. For example, some domestic teams have studied the construction of railway bill of quantities BIM. Starting from the characteristics of cost management of construction enterprises, they have established the cost management system of construction enterprises by using PDCA method. This paper discusses how to carry out the PCM in each stage of the project construction, and points out that the project construction process should be comprehensively controlled according to the project cost budget document, so as to help the enterprise reduce the cost output and improve the economic benefit [1]. Some experts have studied the application of BIMT in project decision-making design, analyzed the current situation faced by construction enterprises, and put forward the strategy of government function transformation in the PCM system adapting to market economy on the basis of establishing the project legal person as the central position. Through the detailed analysis of the bill of quantities in different stages, this paper analyzes the characteristics of the bill of quantities, and puts forward the ways for enterprises to participate in the cost control of PM, so as to give some enlightenment to the theory of project cost control. This paper analyzes the principles and control measures of project cost control from the perspective of system engineering cost and cost control theory, and designs a set of scientific cost control system according to the law of cost itself, which realizes comprehensive management and simplifies cost management and control [2]. Some experts have studied the application of BIMT in building reconstruction, established the system framework, business model and database specification. Starting from the basic principles of PCM, they have analyzed the problems of relatively backward information construction of PCM industry and the need to further improve the quality of personnel, and put forward the improvement of laws and regulations system, Build a scientific and perfect standardized management system. In view of some main problems existing in the current construction cost management in the whole process, this paper puts forward some corresponding countermeasures, puts forward a special cost management scheme, and points out that strengthening the cost management in the construction stage is an inevitable development trend. In view of how to strengthen the PCM, this paper expounds the specific measures and countermeasures for the project cost control from the aspects of organization, technology, economy and contract, and puts forward some specific measures such as perfecting the organization and management mechanism, strengthening the project cost control and strengthening the PCM, so as to scientifically organize and construct, strictly control the project cost and prevent the contract risk. In view of many problems existing in China's PCM, this paper puts forward specific measures to strengthen cost management: setting up special organizations, clarifying responsibilities, reasonably dividing cost modules, strengthening cost prediction, controlling construction stage cost and site management, and achieving cost control objectives 
through the implementation of specific management links [3]. Although the research results of project cost are quite abundant, there are still some deficiencies in the research of PCM strategy under the environment of BD and BIMT.

In order to study the PCM strategy under the environment of $\mathrm{BD}$ and BIMT, this paper studies BD, BIMT and PCM, and finds the method of mutual information feature selection. The results show that it is conducive to the strategy research of PCM under the environment of BD and BIMT.

\section{Method}

\subsection{Big Data and BIM Technology}

\section{(1) Characteristics of big data}

BD has a high universality. The characteristics of BD determine the rapid development of BD in all walks of life [4]. At present, BD has been applied and integrated in almost all industries. BD with its own flexibility, transparency, building blocks, versatility, dynamic, multi leasing and other technical characteristics, can be perfectly integrated with all walks of life. The flexibility of $\mathrm{BD}$ lies in that the delivery modes configured for cloud users can be varied. According to the needs of users, cloud providers can provide three types of public services, namely infrastructure, software and platform services. These delivery models are configured in different combinations [5]. If the cloud environment provided by the supplier can not correct the failure during the peak period of cloud users, it will cause immeasurable losses to users and reduce the overall confidence of cloud users [6]. BD technology adopts data fault tolerance mechanism to ensure the correctness and recoverability of user data. Data resources with strong reliability can better avoid the unexpected situation when users visit, and can recover data resources faster.

(2) BIM Technology Concept

BIMT provides great opportunities for PCM professionals to enable them to greatly improve the quality, speed, accuracy, value and advanced nature of cost management services, thus ensuring their future as key participants in the BIM field. However, the industry is often slow to make full use of the potential that these technologies can offer. As enterprises realize that they must accept these technologies and see competitors seize market advantages by developing professional knowledge in this field, the development momentum is quite strong. BIMT is a systematic method to measure project progress and predict final project cost [7]. However, this method has not been improved in previous versions, and there are some criticisms on the standard method. As long as the cost performance index can get satisfactory results, this method has good conditions [8]. BIM information model not only has the intuitive expression of 3D entity, but also contains more perfect engineering data information. When some data information in the model changes, other information related to it will also change. In addition, the information update of the model is consistent with the changes of each stage of the project life cycle, so as to better manage the project cooperatively. There are many styles of buildings, so it is difficult to describe their specific shape with two-dimensional graphics [9-10].

\subsection{Project Cost Management}

(1) Project cost management concept

PCM is to achieve the predetermined goals and benefits through technology, economy and management[11]. The most valuable data in project cost file is various data, which makes the abnormal data detection problem very important to the early stage of project BD research [12]. In practice, due to the influence of specific construction methods, material types and other objective conditions, the values in the list of works of the same name are not always unchanged, but there are some abnormal values caused by human negligence or intentional. The deviation between these outliers and normal data is not within the normal range. If these abnormal data are directly used for BD analysis, It will have a negative impact on the analysis results, and even get a completely wrong conclusion.

(2) Project cost management and BD

PCM refers to the construction price of a series of projects such as construction engineering, landscape engineering, road traffic engineering, etc. after a long-term development, a large amount of historical data has been accumulated in the field of project cost, mainly structured text documents. The knowledge mining and summary contained in these structured text documents will be helpful for the future development of engineering cost field. Because of the large amount of accumulated data, the combination of engineering cost field and BD technology will bring great changes to a series of work such as data storage, knowledge analysis and mining.

\subsection{Mutual Information Feature Selection Method}

Mutual information method can describe the statistical correlation between feature words and document categories. For feature words and specific document categories $\mathrm{Ci}$, the difference between feature words and document categories can be measured by formula (1), that is, the correlation between feature words and specific categories:

$$
\mathrm{MI}=\left(\text { word }, \mathrm{C}_{\mathrm{i}}\right) \log \frac{\mathrm{P}\left(\text { word }, \mathrm{C}_{\mathrm{i}}\right)}{\mathrm{P}(\text { word }) \mathrm{P}\left(\mathrm{C}_{\mathrm{i}}\right)}
$$

This method describes the information gain of document feature words by counting the frequency of words appearing in a certain type of text and comparing the change of document information entropy before and after words appearing. The formula of information gain Ig (word) of this word can be defined as formula (2):

$$
\mathrm{IG}=(\text { word })=-\sum_{\mathrm{i}-1}^{\mathrm{m}} \mathrm{P}\left(\mathrm{C}_{\mathrm{i}}\right) \log \mathrm{P}\left(\mathrm{C}_{\mathrm{i}}\right)
$$

$M$ is the number of label categories, and $P(d)$ is the value related to the probability of all the feature words in $\mathrm{D}$ in the label set $\mathrm{Ci}$ of all categories. When judging which class $\mathrm{D}$ belongs to, it can be regarded as a constant. 
Therefore, after rounding off, we can get the formula (3):

$$
\mathrm{P}\left(\mathrm{C}_{\mathrm{i}} \mid \mathrm{d}\right)=\mathrm{P}\left(\mathrm{d} \mid \mathrm{C}_{\mathrm{i}}\right) \mathrm{P}\left(\mathrm{C}_{\mathrm{i}}\right)
$$

Convolution layer is mainly used to extract local features from the list. The window width 100 is the dimension of the word vector, and the convolution kernel of the window length $h$ represents $h$ words per convolution. Then the feature $\mathrm{Si}$ extracted by the first convolution is shown in equation (4):

$$
S_{i}=f\left(W \cdot X_{i: h+i-1}+b\right)
$$

\section{Experience}

\subsection{Extraction of Experimental Objects}

Although the calculation formula can be edited according to the actual situation when the quantities are calculated on the itwo project management platform, if the component names are confused at the initial stage of modeling, and the parameter positions cannot be well distinguished, when the components are imported into the platform later, the parameter information in each attribute will be disturbed when the components are filtered. Once the attribute parameter has multiple values, the parameter information will be confused, and the problem of "too many typical values" will appear, and the component cannot be classified. Build load distribution architecture and resource pool architecture. Load distribution architecture can reduce the overuse and underuse of IT resources. By adding one or more of the same it resources to expand the level of IT resources, the load balancer can evenly distribute the workload on the available it resources to maintain load balance. To a certain extent, load distribution architecture relies on complex load balancing algorithm and running logic to better balance the allocation and use of IT resources. The network traffic from the proxy server will flow through a set of management firewalls that isolate the management network boundaries. Servers within the management network boundary provide multiple management servers, and cloud users can access these servers from outside. They support self-service and on-demand allocation of cloud based IT resources.

\subsection{Experimental Analysis}

As PCM, cloud users need to make necessary decisions on how to carry out PCM. Cloud users can build all cloud platform infrastructure, and they can also choose cloud providers or cloud providers that meet the needs of enterprises. Of course, cloud computing services may not require enterprises to build internal servers, but only cloud platform based applications, which also requires enterprise users to calculate costs and make decisions. As a construction enterprise or real estate developer, we can choose more well-designed service products that are satisfied with PCM to support the whole life cycle cloud service of PCM. Enterprises choose platform services suitable for their own enterprises to reduce the cost of enterprises. As cloud users, enterprises can better expand resources to the cloud through the cloud platform, and use the ready-made cloud environment to replace the internal environment of enterprises.

\section{Discussion}

\subsection{Development Trend of China's Construction Industry}

Construction is one of the oldest industries in the world. It plays a very important role in the development of human civilization. At the same time, with the development of human civilization, earth shaking changes are also taking place, especially after the emergence of steel, cement and other building materials, the construction industry has developed rapidly and has become an important pillar industry of the national economy. In recent years, facing the complex and severe situation at home and abroad, China's construction industry will develop slowly in 2020, as shown in Table 1 .

Table 1. Statistical analysis of output value of China's construction industry in 2020

\begin{tabular}{|c|c|c|}
\hline & $\begin{array}{c}\text { Gross output value } \\
\text { of construction } \\
\text { industry } \\
\text { (RMB100mn) }\end{array}$ & $\begin{array}{c}\text { Output value of } \\
\text { Construction } \\
\text { Engineering } \\
\text { (RMB100mn) }\end{array}$ \\
\hline first quarter & 32.5 & 55.4 \\
\hline $\begin{array}{c}\text { Second } \\
\text { quarter }\end{array}$ & 37.6 & 58.3 \\
\hline Third quarter & 47.5 & 67.7 \\
\hline
\end{tabular}

It can be seen from the above that the total output value of construction industry in 2020 will be 3.25 billion yuan in the first quarter, 3.76 billion yuan in the second quarter and 4.75 billion yuan in the third quarter; in 2020, the output value of construction projects will reach 5.54 billion yuan in the first quarter, 5.83 billion yuan in the second quarter and 6.77 billion yuan in the third quarter. The results are shown in Figure 1. 


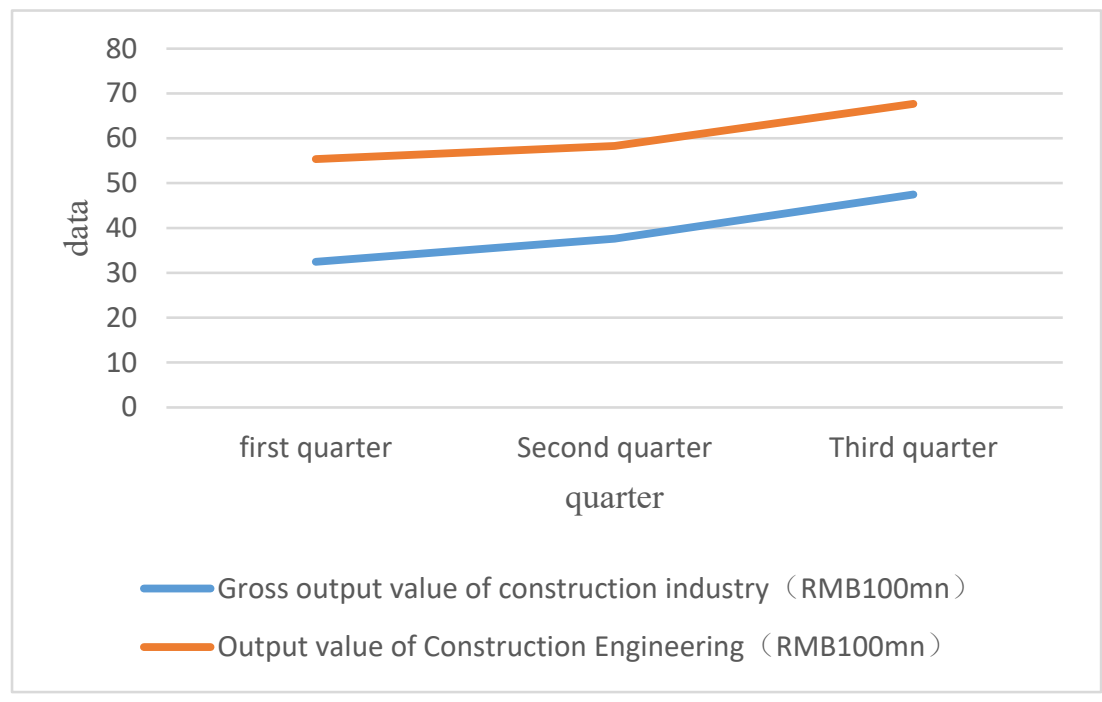

Figure 1. Statistical analysis of output value of China's construction industry in 2020

It can be seen from the above that the output value of China's construction projects will be the largest in 2020, reaching 5.44 billion yuan in the first quarter, 5.83 billion yuan in the second quarter and 6.77 billion yuan in the third quarter. Due to the large number of participants, long construction period and large amount of information in the construction process, these greatly increase the difficulty of project management and PCM, making some cost problems easier to appear.

\subsection{Application Scope and Depth of BIM Technology}

The survey shows that the scope of intelligent application in the construction stage of enterprises is relatively concentrated, as shown in Table 2.
Table 2. Application of BIM Technology function in construction enterprises

\begin{tabular}{|c|c|}
\hline type & data \\
\hline Schedule management & $21.6 \%$ \\
\hline cost control & $19.5 \%$ \\
\hline Control platform & $29.5 \%$ \\
\hline Green construction & $25.8 \%$ \\
\hline
\end{tabular}

It can be seen from the above that the proportion of construction enterprises applying BIMT for progress is $21.6 \%$, the proportion of construction enterprises applying BIMT for cost management is $19.5 \%$, the proportion of construction enterprises applying BIMT Integrated Management and control platform is $29.5 \%$, and the proportion of construction enterprises applying BIMT for green construction is $25.8 \%$. The results are shown in Figure 2.

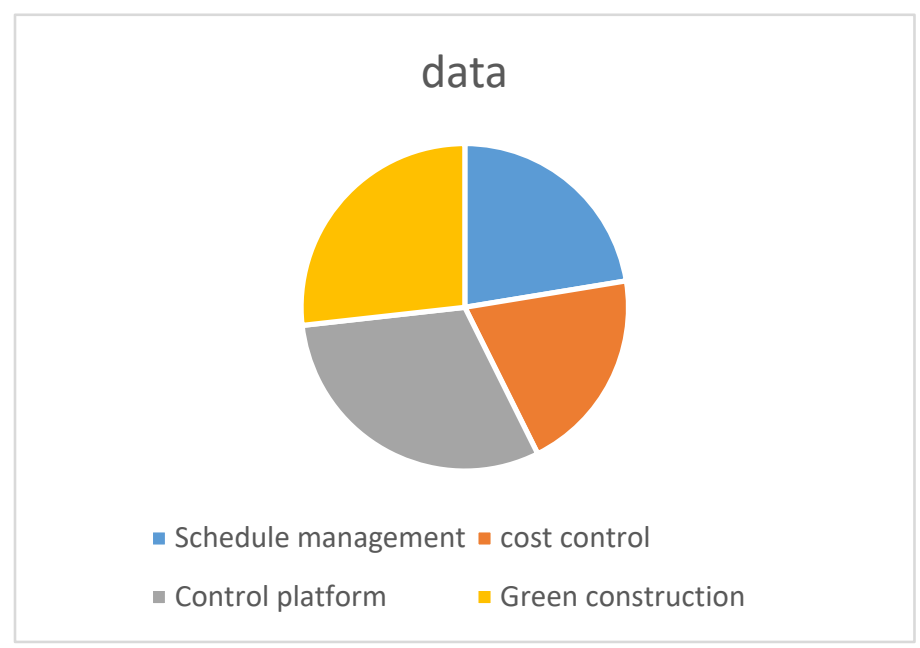

Figure 2. Application of BIM Technology function in construction enterprises

It can be seen that the proportion of construction enterprises applying BIMT for basic management such as progress and cost is relatively large, while the proportion of comprehensive deep application such as comprehensive management and control platform and green construction is relatively low, that is: most enterprises are in the exploration period of BIM application in the construction stage. 


\section{Conclusion}

After half a century of development, PCM methods continue to improve, but compared with the whole social development and construction industry, PCM level is relatively backward. The lack of refinement and informatization leads to poor accuracy and low efficiency of project cost, which restricts the improvement of the comprehensive strength of China's construction industry. Through the comparison with foreign advanced countries, BIMT has been widely used in foreign PCM, which can help the construction industry realize the quantitative analysis of the project and provide scientific and reasonable cost accounting. Therefore, it is necessary to study BIMT and understand the use of BIMT.

\section{Reference}

1. Wang M . Research and Analysis of Contractor Construction Cost Management Based on BIM Technology Platform[J]. 2019, 003(001):P.1-6.

2. Zhang L, Dong Z, Zhang L, et al. Cost Management of Mechanical and Electrical Engineering Project Based on Bim Technology[J].2018, 002(004):P.95-99.

3. Zhang S, Pan F, Shi Y, et al. Collaborative schedule-cost management of hydropower projects based on BIM and $\mathrm{P} 3 \mathrm{E} / \mathrm{C}[\mathrm{J}]$. Shuili Fadian Xuebao/Journal of Hydroelectric Engineering, 2018, 37(10):103-112.

4. Zhou H, Liu K, Zhou D, et al. Project construction process optimization management based on BIM modelling technology[J]. IPPTA: Quarterly Journal of Indian Pulp and Paper Technical Association, 2018, 30(7):360-370.

5. Marzouk M , Enaba M . Analyzing project data in BIM with descriptive analytics to improve project performance $[\mathrm{J}]$. Built environment project and asset management, 2019, 9(4):476-488.

6. Naml E, Ikda M , Kocakaya M N . Building Information Management (BIM), A New Approach to Project Management[J]. Journal of Sustainable Construction Materials and Technologies, 2019, 4(1):323-332.

7. Meisaroh M, Husin A E, Susetyo B . Analysis of Key Success Factors Using RII Method on The Implementation Building Information Modeling (BIM)-Based Quantity Take-Off to Improve Cost Performance Hospital Structure[J]. Solid State Technology, 2021, 64(2):3179-3188.

8. Yismalet A , Patel D . A CRITICAL LITERATURE REVIEW ON IMPROVING PROJECT COST MANAGEMENT PRACTICE AND PROFITABILITY OF DOMESTIC CONTRACTORS[J]. International Journal of Engineering Technologies and Management Research, 2020, 5(1):51-58.

9. Toosi H , Chamikarpour A . A New Cost Management System for Construction Projects to increase Competitiveness and Traceability in a Project Environment[J]. Revista de Contabilidad, 2021, 24(1):31-47.

10. Yan M . Resource-based Optimization Model for Dynamic Project Planning and Cost Management[J]. Applied Mathematics \& Information Sciences, 2017, 11(4):1091-1096.

11. HU Jinlan, B Wang, J Dong. Analysis on Cost Management Status Quo and Development Trend of Distribution Network Project[J].2019, 006(002): 106-111.

12. Discussion on Project Cost Management and Budget Compilation in China[J]. Management Science and Engineering, 2021, 10(1):32-39. 